\title{
TABLES INCLUDED IN THE TEXT
}

Table 1 Number of varieties of foodstuffs consumed by the aborigines of Groote Eylandt and the Dieri (after WorsLEY and Gason) . . . . . . . . . 15

2 Classificatory terms of relationship of the Groote Eylandt aborigines . 18

3 Original lettering of classificatory terms of relationship . . . . . . . 30

4 Estimation of "experimental error" in identification: sample 1 . . . . 40

5 Estimation of "experimental error" in identification: sample 2 . . . . 40

6 Categories of relationship: relationship A . . . . . . . . . . . . . 55

7 Categories of relationship: relationship B . . . . . . . . . . . . . 56

8 Categories of relationship: relationship C . . . . . . . . . . . . . 56

9 Categories of relationship: relationship D . . . . . . . . . . . . . 56

10 Categories of relationship: relationship E . . . . . . . . . . . . 57

11 Categories of relationship: relationship $\mathrm{F}$. . . . . . . . . . . . . 57

12 Categories of relationship: relationship $\mathrm{G}$. . . . . . . . . . . . . 57

13 Categories of relationship: relationship $\mathrm{H}$. . . . . . . . . . . . . 58

14 Categories of relationship: relationship I . . . . . . . . . . . . . . 58

15 Categories of relationship: relationship $\mathrm{J}$. . . . . . . . . . . . . . 58

16 Categories of relationship: relationship K . . . . . . . . . . . . . . . . 59

17 Categories of relationship: relationship L . . . . . . . . . . . . . 59

18 Categories of relationship: relationship $M$. . . . . . . . . . . . . 59

19 Categories of relationship: relationship $\mathrm{N}$. . . . . . . . . . . . . . . . 60

20 Categories of relationship: relationship $\mathrm{O}$. . . . . . . . . . . . . . 60

21 Groote Eylandt population sample according to age groups and sex . . 61

22 Groote Eylandt population sample: age groups above 21 years expressed as a percentage of totalled population sampled above 21 years according to sex . . . . . . . . . . . . . . . . 61

23 Age of man and wife (wives) according to moieties . . . . . . . . 64

24 Age of man and wife (wives) where wife is 20 or less years old, according to moieties. . . . . . . . . . . . . . . . . . . . . . . . . . . 65

25 Age of man and wife (wives) where wife is over 20 and less than 36 years of age . . . . . . . . . . . . . . . . . . 66

26 Age of man and wife (wives) where wife is 36 years of age or over . . 66

27 Number of men in each age group according to the number of wives each man has . . . . . . . . . . . . . . . . . . . . . . . . . . . . 69

28 Number of wives per married man according to age group of man: and number of women per man (all men) in each age group . . . . . . 69

29 Number of men to whom a woman has been wife . . . . . . . . . . 72

.. 30 Number of men to whom a man has been initiate . . . . . . . . . . 73 


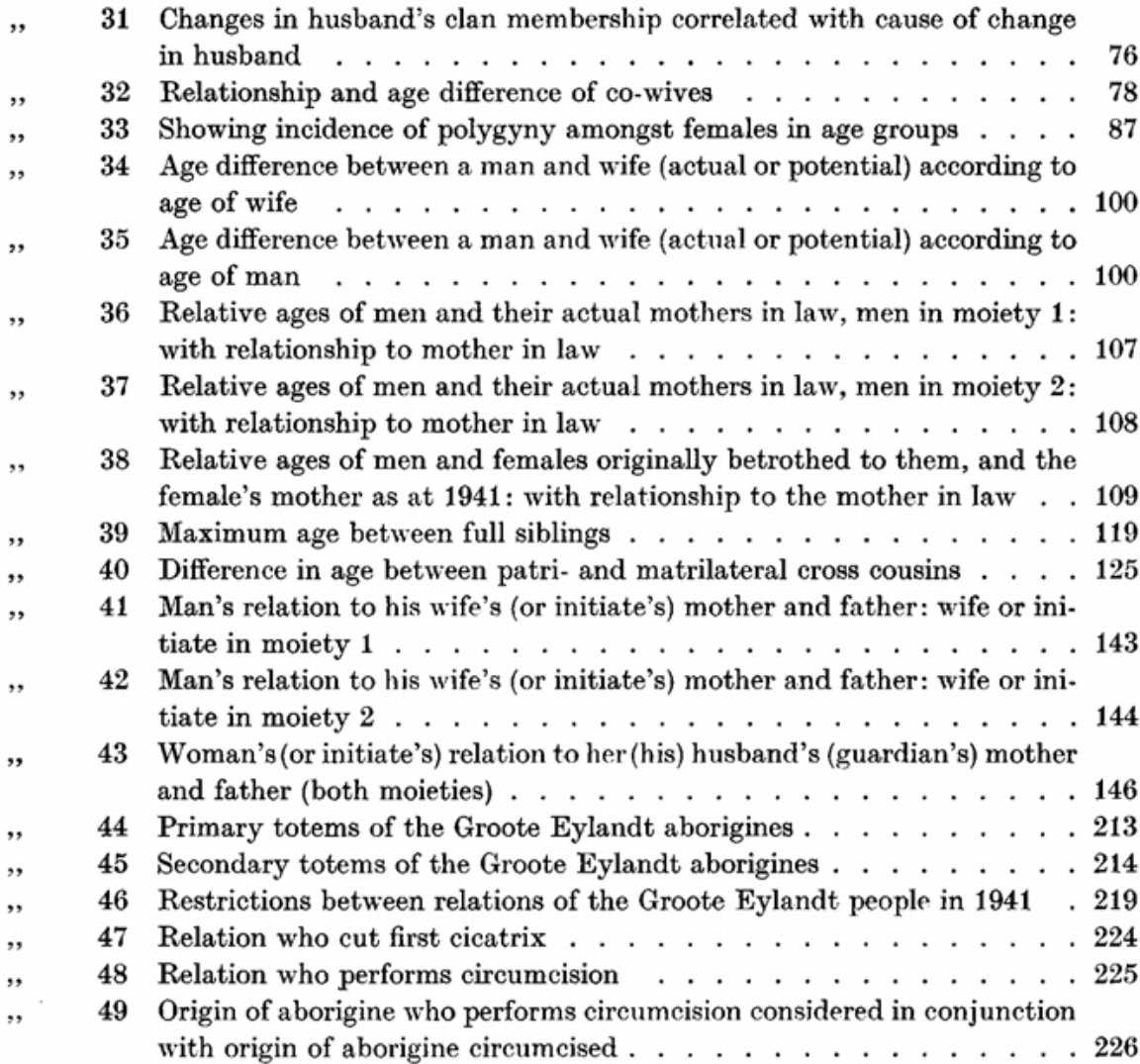

\section{LIST OF DIAGRAMS}

1 Curve used to "re-assess" ages of aborigines in moiety 1 . . . . . . . . . . . . 46

2 Curve used to "re-assess" ages of aborigines in moiety 2 . . . . . . . . . . . . . 47

3 Showing relative ages of males and their actual or potential wives . . . . . . . . 67

4 Showing incidence of polygyny amongst females in age groups . . . . . . . . . . . 88

5 Showing relative ages of males and those females who call each other reciprocally " $\mathrm{O} / 0$ " 138

6 Illustrating the "typical" marriage of the Groote Eylandt society . . . . . . . . 148 